\title{
Comparison of central corneal thickness (CCT) and intraocular pressure (IOP) in patients with pseudoexfoliation and healthy individuals without pseudoexfoliation
}

\author{
Ksheeraja Y, Ramya M \\ MS Ramaiah Medical College, Bangalore, India
}

\begin{abstract}
BACKGROUND: The aim of a study was to compare the central corneal thickness (CCT) and intraocular pressure (IOP) in patients with pseudoexfoliation (PXF) and age-matched healthy individuals without PXF.

MATERIAL AND METHODS: This prospective comparative study was conducted at the Medical College Hospital in South India. The study was conducted on 100 patients who were divided into two groups. Patients with PXF were categorized as group 1 (50 patients) and healthy normal individuals without PXF as group 2 (50 patients). Visual acuity was recorded using Snellen's visual acuity chart. Anterior segment examination was done using a slit lamp. Central corneal thickness was measured using ultrasonic pachymetry. Intraocular pressure was measured using Goldmann applanation tonometer and corrected intraocular pressure (IOP) after pachymetry.

RESULTS: In group 1 mean age of patients was $64.76 \pm 5.5$ years. 18 (32\%) were females, $32(64 \%)$ were males. In group 2 mean age was $61.56 \pm 5.1$ years, with $29(58 \%)$ males and 21 (42\%) females. Central corneal thickness was significantly thinner in patients with PXF than in controls. The mean CCT in the PXF group was $536 \pm 24$ microns and the control group $561 \pm 25$ microns with a p-value of 0.03 , which was statistically significant. Mean corrected IOP in the PXF group was $16.698 \pm 6.70 \mathrm{~mm} \mathrm{Hg}$, and in the control group was $13.66 \pm 2.14 \mathrm{~mm} \mathrm{Hg}$ with p-value 0.00 , which was statistically significant.

CONCLUSION: The study shows that corneas are thinner in patients with PXF as compared to controls. Hence CCT should be done in all the PXF patients, and the corrected IOP should be measured to prevent the false low estimation of IOP.
\end{abstract}

KEY WORDS: PXF; pseudoexfoliation; IOP; intraocular pressure; corrected IOP; corrected intraocular pressure; CCT; central corneal thickness 


\section{INTRODUCTION}

Pseudoexfoliation syndrome (PXF) is a microfibrillopathy with a genetic component. Single nucleotide polymorphism (SNP) of lysyl oxidase 1 gene (LOXL1) located on chromosome 15 is responsible for pseudoexfoliation syndrome and glaucoma [1].

Pseudoexfoliation syndrome is characterized by the production and accumulation of extracellular fibrillary material in various body tissues. Characteristic whitish powdery flake material is deposited over several ocular structures, including corneal endothelium, pupillary margin, anterior lens capsule (as shown in Fig. 1), zonules, ciliary body, trabecular meshwork. It is the most common cause of secondary open-angle glaucoma.

PXF diagnosis often requires a careful slit-lamp examination after pupillary dilation, and this condition frequently remains undiagnosed [2].

Central cornea thickness (CCT) is an integral component in the workup of any new patient suspected of having glaucoma. The CCT can be influenced by many factors, including ethnicity, genetics, age, glaucoma treatment, and the subtype of glaucoma. The measurement of CCT by the various devices is also not interchangeable. All these above factors need to be considered in the evaluation of glaucoma.

Goldmann applanation tonometry (GAT) has become the international "gold standard" for IOP measurements. A thick cornea would overestimate IOP, and a thin one would underestimate it.

This study aims to analyze and compare CCT in PXF patients and normal healthy individuals, which is one of the important independent variables in measuring accurate IOP.

\section{MATERIALS AND METHODS}

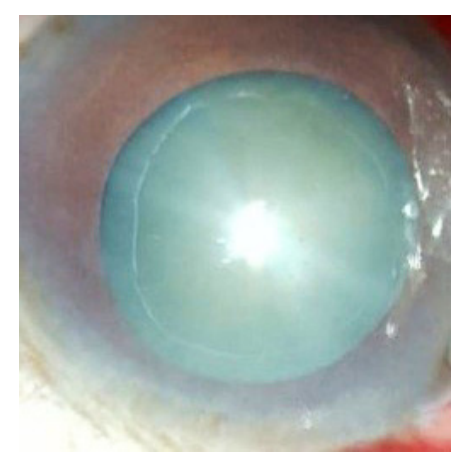

FIGURE 1. Pseudoexfoliation material deposited over the anterior lens capsule
This was a prospective comparative case-control study conducted at a Medical College Hospital in South India. The study was conducted on 100 patients who were divided into two groups. Patients with PXF were categorized as group 1 (50 patients) and healthy normal individuals without PXF as group 2 (50 patients). Written informed consent was obtained from all the patients participating in the study. Visual acuity was recorded using Snellen's visual acuity chart, and anterior segment examination was done using a slit-lamp biomicroscopy.

Central corneal thickness was measured using ultrasonic pachymetry. Ultrasound pachymetry was used to measure the central corneal thickness by a single observer. After a drop of anesthetic, repeated sets of five readings at the center of the cornea were taken until the standard deviation for the five readings was $5 \mu \mathrm{m}$ or less.

Intraocular pressure was measured using a Goldmann applanation tonometer. Corrected IOP was measured after doing corneal ultrasonic pachymetry. Gonioscopy was performed to evaluate the angle structures and grade the angle by Shaffers grading. Dilated fundus examination was done, and optic disc changes were documented.

\section{Inclusion criteria}

Inclusion criteria were as follows:

- all patients with PXF were included in group 1;

- age-matched healthy individuals without PXF were included in group 2 (control).

\section{Exclusion criteria}

Exclusion criteria were as follows:

- previous ocular injury;

- history of ocular surgeries;

- corneal opacity;

- preexisting glaucoma.

\section{RESULTS}

This study was conducted on 100 patients, divided into two groups.

Patients with PXF were categorized as group 1 and healthy normal individuals without PXF as group 2. The age and sex distribution of the patients with and without PXF is presented in Tables 1 and 2 .

In group 1 (patients with PXF) mean age was $64.76 \pm 5.5$ years. Among the 50 PXF patients, $18(32 \%)$ were females, $32(64 \%)$ were 


\begin{tabular}{|l|c|c|}
\hline \multicolumn{3}{|l|}{ Table 1. Age distribution of the patients } \\
\hline Age [years] & Group 1 & Group 2 \\
\hline $50-59$ & $1(2 \%)$ & $16(32 \%)$ \\
\hline $60-69$ & $38(76 \%)$ & $30(60 \%)$ \\
\hline$\geq 70 \mathrm{e}$ & $11(22 \%)$ & $4(8 \%)$ \\
\hline Total & $50(100 \%)$ & $50(100 \%)$ \\
\hline
\end{tabular}

\begin{tabular}{|c|c|c|c|}
\hline & Number & Males & Females \\
\hline Group 1 & 50 & $32(64 \%)$ & $18(32 \%)$ \\
\hline Group 2 & 50 & $29(58 \%)$ & $21(42 \%)$ \\
\hline
\end{tabular}

Table 3. Comparison of mean intraocular pressure
distribution among group 1 and group 2
\begin{tabular}{|l|c|c|c|}
\hline & Number & IOP (mean) [mm Hg] & p-value \\
\hline Group 1 & 50 & $16.66 \pm 6.59$ & \multirow{2}{*}{0.048} \\
\hline Group 2 & 50 & $14.72 \pm 1.79$ & \\
\hline
\end{tabular}

$\mathrm{IOP}$ - intraocular pressure

males. In group 2 (patients without PXF) mean age was $61.56 \pm 5.1$ years, with $29(58 \%)$ males and $21(42 \%)$ females.

The IOP was measured using Goldmann's applanation tonometer for all the patients. Mean IOP in group 1 was $16.66 \pm 6.59 \mathrm{~mm} \mathrm{Hg}$ compared to the mean IOP of $14.72 \pm 1.79 \mathrm{~mm} \mathrm{Hg}$ in group 2 (Tab. 3). The mean IOP in groups was compared by an independent sample test. It was not statistically significant ( $\mathrm{p}$-value $=0.048$ )

Central corneal thickness was measured using ultrasonic pachymetry in all patients in both groups. The CCT central corneal thickness was divided into ranges and observed for the frequencies in both groups (Tab. 4).

In group $1,10 \%$ of patients had corneas $<500$ microns, whereas, in group 2, none had cornea $<500$ microns. Hence PXF patients in group 1 had a false low reading of IOP measurement due to thinner corneas.

Mean CCT in group 1 was 0.536 microns, whereas in group 2, it was 0.561 microns. The means were compared with the independent sample test, which showed a comparative p-value of 0.00 (statistically significant, Tab. 5).
Table 4. Central corneal thickness (CCT) distribution in group 1 and group 2

\begin{tabular}{|l|c|c|}
\hline CCT (microns) & Group 1 & Group 2 \\
\hline $400-450$ & $1(2 \%)$ & 0 \\
\hline $451-500$ & $4(8 \%)$ & 0 \\
\hline $501-550$ & $36(72 \%)$ & $20(40 \%)$ \\
\hline $551-600$ & $9(18 \%)$ & $26(52 \%)$ \\
\hline $601-660$ & 0 & $4(8 \%)$ \\
\hline Total & $50(100 \%)$ & $50(100 \%)$ \\
\hline
\end{tabular}

Table 5.Comparision of mean central corneal thickness (CCT) among group 1 and group 2

\begin{tabular}{|l|c|c|c|}
\hline & Number & CCT (mean ) & p-value \\
\hline Group 1 & 50 & $536 \pm 24$ microns & \multirow{2}{*}{$0.00(<0.04)$} \\
\hline Group 2 & 50 & $561 \pm 25$ microns & \\
\hline
\end{tabular}

Table 6. Corrected intraocular pressure (IOP)

distribution among group 1 and group 2

\begin{tabular}{|l|c|c|}
\hline $\begin{array}{l}\text { Corrected IOP } \\
\text { [mm HG] }\end{array}$ & $\begin{array}{c}\text { Group1 } \\
\text { Frequency } \\
\text { (percentage) }\end{array}$ & $\begin{array}{c}\text { Group2 } \\
\text { Frequency } \\
\text { (percentage) }\end{array}$ \\
\hline $10-15$ & $25(50 \%)$ & $42(76 \%)$ \\
\hline $16-20$ & $14(28 \%)$ & $8(16 \%)$ \\
\hline $21-25$ & $7(14 \%)$ & 0 \\
\hline $26-30$ & $3(6 \%)$ & 0 \\
\hline$>31$ & $1(2 \%)$ & 0 \\
\hline Total & $50(100 \%)$ & $50(100 \%)$ \\
\hline
\end{tabular}

After doing ultrasonic corneal pachymetry and obtaining the central corneal thickness values, corrected IOP was calculated for all the patients.

The corrected IOP distribution was divided into ranges and observed for the frequencies in both groups (Tab. 6).

In group 1,11 patients (22\%) had high IOP $>20 \mathrm{~mm} \mathrm{Hg}$, whereas in group 2, all patients had normal IOP $<20 \mathrm{~mm} \mathrm{Hg}$.

Corrected IOP among both groups was compared and analyzed by an independent sample test. The mean corrected IOP in group 1 was $16.698 \pm 6.70 \mathrm{~mm} \mathrm{Hg}$, whereas, in group 2, it was $13.66 \pm 2.14 \mathrm{~mm} \mathrm{Hg}$. The difference was statistically significant with a p-value of $0.003(<0.04)$ (Tab. 7).

Gonioscopy was performed using Goldmann 3 mirror lens. Shaffers grading was used to grade the angles, which showed open angles in all patients. 
Table 7. Comparision of mean corrected intraocular pressure (IOP) among group 1 and group 2

\begin{tabular}{|l|c|c|c|}
\hline & Number & $\begin{array}{c}\text { Corrected IOP (mean) } \\
{[\mathrm{mm} \mathrm{Hg}]}\end{array}$ & p-value \\
\cline { 1 - 3 } Group 1 & 50 & $16.69 \pm 6.70$ & \multirow{2}{*}{0.003} \\
\hline Group 2 & 50 & $13.66 \pm 2.14$ & \\
\hline
\end{tabular}

Dilated fundoscopy performed in group 1 showed 11 patients with the cup - disc ratio of $>0.6$ with corrected IOP $>21 \mathrm{~mm} \mathrm{Hg}$ - suggested pseudoexfoliative glaucoma (PXG).

\section{DISCUSSION}

Glaucoma is the primary cause of irreversible blindness. World Health Organization (WHO) statistics indicate that glaucoma is the second leading cause of blindness. Pseudoexfoliation is the most common cause of secondary open-angle glaucoma.

Blue Mountains eye study showed that the incidence of glaucoma in eyes with PXF is nine times higher. They are associated with thinner corneas, which leads to a false low IOP [3].

Corrected IOP measurement is crucial in diagnosing and managing glaucoma, but invariably, various errors may affect the accuracy of measurements.

Various studies reported that thicker corneas lead to false high IOP and thinner corneas to false low IOP [4]. Gordon et al. [5] reported that a thin cornea was a risk factor for developing glaucoma. The risk of conversion in patients with CCT $<555 \mu \mathrm{m}$ was over three times higher than in patients with corneas $>588 \mu \mathrm{m}$ thick.

In our study, the mean age of patients with PXF was $64.76 \pm 5.5$ years. Among the 50 PXF patients, $18(32 \%)$ were females, $32(64 \%)$ were males. In patients without pseudoexfoliation mean age was $61.56 \pm 5.1$ years. In this group, $29(58 \%)$ were males, and 21 (42\%) were females.

A study conducted by Krysik et al. showed that the mean age of the study group was $73 \pm 7.8$ years (range:49-88 years), and that of the control group was $69 \pm 9.3$ years. 7 (range: $45-84$ years). There was no statistically significant difference concerning gender and age between both groups $(p>0.05)$.

In our study, among the 50 PXF patients, $18(32 \%)$ were females, and $32(64 \%)$ were males. Thus, our study noted male preponderance similar to the studies done by Nishat et al. [8], where the male: female ratio in the PXF group was 1.7:1 and in the PXG group was 2.6:1.

In a study performed by Mccarty al. [9], 46\% of PXF patients were men in the urban population, and $48 \%$ were men in the rural population. These results were similar to those obtained in our study, where the majority were males.

Spoorthy et al. found that in PXF eyes, CCT was thinner compared to the control eyes (statistically significant $-\mathrm{p}<0.05)$ [10]. The resultss of a study conducted by Brindavolu et al. were similar - the CCT was thin in PXF group and PXG group [11].

In our study, the mean IOP in the group with PXF was $16.66+/-6.59 \mathrm{~mm} \mathrm{Hg}$, in the control group $-14.72+/-1.79 \mathrm{~mm} \mathrm{Hg}$. The mean IOP before adjusting for CCT value was almost similar in both groups ( $\mathrm{p}$-value $=0.048$, the difference was not statistically significant).

CCT measurement in both groups was statistically significant ( $\mathrm{p}$-value $=0.00$ ): patients with PXF had significantly thinner corneas; hence, false low IOP measurements were recorded. The difference in corrected IOP after CCT correction among the two groups was statistically significant too. (pvalue $=0.03$ ).

A study conducted by Priyadarshini et al. found that the mean IOP was similar in both eyes of the control group. In the PXF group, the mean IOP was $13.1 \mathrm{~mm} \mathrm{Hg}$ and $13.2 \mathrm{~mm} \mathrm{Hg}$ in the right and left eyes. There was an increase of about $3.1 \mathrm{~mm} \mathrm{Hg}$ in the corrected IOP of both eyes, which was statistically significant $(\mathrm{p}$-value $=0.000)[12]$.

\section{CONCLUSION}

Our study shows that CCTs are thinner in patients with PXF as compared to controls without PXF. CCT should be performed in all patients with PXF and corrected IOP should be measured to prevent the false low estimation of IOP.

The early detection of glaucoma and its progression can be prevented by measuring CCT and corrected IOP in all patients with PXF.

\section{Funding}

None declared

\section{Conflicts of Interest}

None declared. 


\section{REFERENCES}

1. Thorleifsson G, Magnusson KP, Sulem $P$, et al. Common sequence variants in the LOXL1 gene confer susceptibility to exfoliation glaucoma. Science. 2007; 317(5843): 1397-1400, doi: 10.1126/ science.1146554, indexed in Pubmed: 17690259.

2. Ritch R, Schlötzer-Schrehardt U. Exfoliation Syndrome. Surv Ophthalmology. 2001; 45(4): 265-315, doi: 10.1016/s0039-6257(00)00196-x, indexed in Pubmed: 11166342.

3. Tan JSL, Wang JJ, Flood V, et al. Blue Mountains Eye Study, Blue Mountains Eye Study. Diabetes, fasting blood glucose and age-related maculopathy: The Blue Mountains Eye Study. Aust N Z J Ophthalmol. 1999; 27(3-4): 197-199, doi: 10.1046/j.1440-1606.1999.00211.x, indexed in Pubmed: 10484190.

4. Özcura F, Aydin S, Dayanir V. Central Corneal Thickness and Corneal Curvature in Pseudoexfoliation Syndrome With and Without Glaucoma. J Glaucoma. 2011; 20(7): 410-413, doi: 10.1097/ IJG.0b013e3181f7afb8., indexed in Pubmed: 21278594.

5. Gordon MO, Beiser JA, Brandt JD, et al. The Ocular Hypertension Treatment Study: baseline factors that predict the onset of primary open-angle glaucoma. Arch Ophthalmol. 2002; 120(6): 714-20; discussion 829, doi: 10.1001/archopht.120.6.714, indexed in Pubmed: 12049575.

6. Hepsen IF, Yağci R, Keskin U. Corneal curvature and central corneal thickness in eyes with pseudoexfoliation syndrome. Can J Ophthalmol.
2007; 42(5): 677-680, doi: 10.3129/i07-145, indexed in Pubmed: 17891195.

7. Krysik K, Dobrowolski D, Polanowska K, et al. Measurements of Corneal Thickness in Eyes with Pseudoexfoliation Syndrome: Comparative Study of Different Image Processing Protocols. J Healthc Eng. 2017; 4315238, doi: 10.1155/2017/4315238., indexed in Pubmed: 29081937.

8. Sultana N. Evaluation of Central Corneal Thickness and clinical ocular profile of Patients presenting with Pseudoexfoliation at a tertiary care centre. Indian J Clin ExOphthalmol. 2019; 5(4): 543-551, doi: 10.18231/j.jijceo.2019.126.

9. Mccarty CA, Taylor HR. Pseudoexfoliation syndrome in Australian adults. Am J Ophthalmol. 2000; 129(5): 629-633, doi: 10.1016/ s0002-9394(99)00466-3, indexed in Pubmed: 10844055.

10. Spoorthy $S$, Chandra $S$. Central corneal thickness and curvature changes in pseudoexfoliation eyes in comparison with normal eyes. Int J Health Clin Res. 2020; 3(5): 63-66.

11. Firdous SG, Asritha B, Kaveripakam SR, et al. Comparision of central corneal thickness in pseudoexfoliation syndrome and pseudoexfoliation glaucoma. IP Int J Ocul Oncol Oculoplasty. 2019; 5(4): 229-232, doi: 10.18231/j.jj000.2019.053.

12. Padmanaban S, Sathya Priya P, et al. Central Corneal Thickness In Individuals With And Without Pseudo Exfoliation Syndrome - A Prospective Study. J Dent Med Sci. 2018; 17(5): 19-23, doi: 10.9790/08531705071926 . 